\title{
Satish Dhawan: Refractions from another time*
}

\author{
Venkatasubbiah Siddhartha ${ }^{1, \dagger}$ and Yagnaswami Sundara Rajan ${ }^{2}$ \\ ${ }^{1}$ International Strategic Studies Programme, National Institute of Advanced Studies, Bengaluru 560 012, India \\ ${ }^{2}$ Former Scientific Secretary ISRO/Former Dr Vikram Sarabhai Distinguished Professor ISRO/DOS, ISRO Headquarters, Bengaluru 560 231, India
}

\section{A preword}

REMINISCING about his time at the California Institute of Technology (Caltech), USA, the late Sitaram Rao Valluri (Director, National Aeronautical Laboratory, NAL), related to me an occasion when, in a conversation at Caltech with the legendary Hans Liepmann, the latter pointed to a blackboard with 'Satish's writing on it'. Liepmann said he had sprayed the board with a transparent coating so 'it could not be rubbed off'.

'Each time I had a difficult decision to make at NAL', Valluri confessed to me, 'I would ask myself: "Would Satish approve?",

During its composition, the draft title ('SD: A Ratna of Bharat') of this essay, and several paragraphs drifted into hagiography - albeit sincere. On each such, I have had to apply the 'Valluri test': With each successive draft failing that test, this essay has had to be revised several times into the text that appears here.

It has been difficult.

\section{About this contribution}

In an article written for the Indian National Science Academy (INSA), New Delhi on Satish Dhawan's foundational and seminal contributions to our space programme, Rajan ${ }^{1}$ has identified a meeting in 1972 in Ahmedabad as having seeded the formulation of the first profile of the then recently formed Department of Space (DoS) of the Government of India (GoI).

That first decadal profile ${ }^{2}$, with emphasis on applications of space technology, carried the imprimatur of Satish Dhawan (SD) - the engineer. That profile laid out - for the first time - two overlapped half-decadal projections of the programmes, projects, R\&D activities, and test and support facilities of DoS, together with the projected expenditures on them, and aligned these with the national Five-Year Plans on the Science and Technology (S\&T) sector.

Envisaged collaborations with industry were made integral to that profile by including in the projected

Venkatasubbiah Siddhartha and Yagnaswami Sundara Rajan were colleagues (1974-82) in the Systems Planning and Analysis Group formed by Satish Dhawan at the Indian Space Research Organisation, Headquarters in Bengaluru.

*Use here of the first-person, singular refers to the first author who bears exclusive responsibility for the opinions expressed herein.

'For correspondence. (e-mail: scatopsa@gmail.com) financial outlays a line item on 'technology transfer and utilization'. That line item has now grown into the business plans of two commercial enterprises of $\operatorname{DoS}^{3}$.

Accounts by other Indian Space Research Organisation (ISRO) insiders (e.g. refs 4-6) have expatiated in their respective distinctive styles the techno-managerial nittygritty of the execution of launch vehicle and satellite programmes of ISRO $^{4-6}$. Also revealed in them are decisions made under SD's watch for the early seeding and subsequent sprouting of a comprehensive portfolio of long-gestation enabling technologies and test facilities, for liquid propulsion systems in particular.

So, this essay is mostly about my interactions with Dhawan on matters concerning the warp and weft of his contributions to, and concerns with, the fashioning of the nation's broader S\&T policy - outside of ISRO - at a special time in the country's post-independence history; the times soon after the liberation of Bangladesh. However, I have concluded with a section on Sriharikota, the space-launch island North of Chennai that SD particularly cared about, and now appositely named in his remembrance as the Satish Dhawan Space Centre.

While much of what follows is based on my handwritten notes of conversations that I had with SD, or on transcriptions of hand-written notes from him to me, some events have been sourced from memory.

\section{On broader S\&T policy}

The evolution of the nation's S\&T policies since independence, and the role(s) of the top layers of the scientific establishment in their formulation and execution, have been dilated on in a contribution to a UNESCO series ${ }^{7}$. A reading of that reference will provide the required historical background and context to what appears below.

\section{The Scientific Policy Resolution}

'Who was really responsible for the Scientific Policy Resolution?', I asked SD, now well into his retirement. 'K. Chandrasekharan and Bhabha', he replied. The former (KC) had moved to the Eidgenossische Technische Hochschule (ETH), Zurich from the Tata Institute of Fundamental Research (TIFR) in Mumbai ${ }^{8}$.

Intrigued, I addressed a query letter to $\mathrm{KC}$ at ETH. I received in May 1996 from KC's secretary a reply which read: 'I have been asked by him to confirm what 
Prof. Satish Dhawan has "let be known", that the Scientific Policy Resolution of the Government of India, 1958, was indeed drafted by him, at the instance of the late Dr H. J. Bhabha, with two phrases amended by the Cabinet. A draft text, of a couple of pages, offered by Prof. D. S. Kothari, was considered as a preamble or annex." ${ }^{9}$.

In the Cabinet Secretariat there can be found attached to a text of the draft Scientific Policy Resolution (SPR) a slip from 'Secretary, Department of Atomic Energy', which reads: 'The Prime Minister wished to have the draft of the Resolution on Government's Scientific Policy proposed by the Scientific Advisory Committee to the Cabinet. It is sent herewith.' (Signed) H. J. Bhabha, 13, $12 / 57$, marked to 'Prime Minister'.

I doubt if 'Jawaharlal' - as Bhabha addressed the PM with familiarity - ever got to know who the real drafterauthor was.

\section{The attempt to restructure the Council of Scientific and Industrial Research}

In 1977, the Janata Government under Morarji Desai as Prime Minister (PM) appointed Atma Ram as VicePresident of the Council of Scientific and Industrial Research (CSIR), and as the new Chairman of the National Committee on Science and Technology (NCST). Not long afterwards in August of that year, the Cabinet approved a proposal for a 'restructuring' of the CSIR, which called for a clutch of its identified laboratories to be brought under the administrative control of what was termed as the 'user Ministries'. A Press Release on the Cabinet decision stirred the usually placid world of S\&T into a cauldron of rumour, intrigue, double-speak and prevarication amongst the top echelons of the scientific community: A full narration of these shenanigans would qualify for a best-selling thriller.

On 25 August, I asked SD if he was considering this matter in the Indian Academy of Sciences, Bengaluru. 'Something will have to done', he answered: 'Maybe an Academy Resolution to the effect that Government should consult the scientific community. They can take their own decisions; they do not have to kow-tow to the scientists, but they must consult'.

'Why don't you talk to Cab. Sec.', I made bold to suggest.

'They are cagey on such things - the old Civil Service network set-up. Thing to do is to talk to the Prime Minister. I'll be ticked-off, but so what?', he proffered.

Much later, in the first-floor lobby of the Indian Institute of Science, I hovered at a little distance away from a knot of SD, Raja Ramanna and A. K. N. Reddy (who had been a scientist with CSIR in its Central ElectroChemical Research Institute in Karaikudi). Ramanna handed SD a copy of the Resolution that had earlier been passed by INSA.
'They cannot just put a red line through CSIR', said $\mathrm{SD}$, spreading his palm over the paper Ramanna had just handed him.

Later that October, prior to a scheduled meeting of the NCST, SD apprised Morarji Desai of the sentiment in the Indian Academy of Sciences. The PM showed SD the speech he was to make at the NCST, and asked to be pointed out any 'objectionable parts'.

'There was nothing in it that I could object to', SD confided to me.

\section{The Departments of Electronics, $S \& T$ and 'Goku' Menon}

In diverse professional writings by several authors, and even more by commentators in the media, much has been said about the history, purposes, mandate and functioning of the Department of Electronics, GoI, ever since that Department's inception. For an authentic insider's account, I recommend one by (the late) Ashok Parthasarathi: https://frontline.thehindu.com/science-and-technology/theroad-to-it-greatness/article9968229.ece

My purpose here is to relate SD's account and assessment of the leadership changes in the Departments of Electronics, and of Science and Technology (DST) that were effected not long after a new Government under PM Morarji Desai took office in March 1977.

The PM had called M. G. K. Menon and asked what he thought should be done with DST, suggesting that he take it over. Menon asked for time to think it over. During the time the PM had granted, Menon asked SD (who affectionately called Menon 'Goku') what he should do. 'Up to you to decide what you want to do with your life', responded SD, 'but if I were you, I would take it, because if DST came under charge of a "screwy character" (sic), things would be real bad.'

So Menon accepted the DST appointment, holding temporary charge of Electronics.

Menon learnt of his succession in Electronics not from the PM, but through a copy to him of the O.M. from Cabinet Secretariat conveying the appointment of Biswajit Nag as Secretary, Department of Electronics. SD's appreciation of the nuances of that kind of bureaucratic foot-work tended him 'now to agree that Goku's shift to DST was probably a move to ease him out of Electronics'.

\section{On relations between space and defence}

\section{Reconnaissance satellites}

In 1977, India's first low-orbit remote-sensing satellite, Bhaskara-I, was still in its early making, and the country's first test launch of its own Satellite Launch Vehicle (SLV) was some two years away. 
Yet, preciently on 9 December of that year, Menon, who was the then Scientific Adviser to the Defence Minister (RM), had arranged a presentation by SD as Secretary, DoS, to the Chiefs of Staff.

Rajan, who was in attendance, prepared the presentation material for the meeting which was almost entirely about reconnaissance satellites and the launch capabilities required to place them in the desired orbits.

As Rajan later related to me, 'Mooli' (Air Chief Marshal Hrushikesh Moolgavkar) asked what ISRO was doing explicitly in the matter. 'Nothing; said SD. 'We have not been asked'.

Later mid-month, informally recalling the event, SD reflected: 'It went off OK. Don't know how much they knew of the background. But there is some interest. Some follow-up. Things will have to move through RM.'

\section{Missiles}

For the duration of SD's tenure as Chairman of ISRO and Secretary of DoS, the relationship between ISRO and Defence R\&D on missiles remained tense at policy level; a tenseness I attribute as much to the not-so-hidden differences in the personalities and attitudes of SD and the leadership of Defence $R \& D$, as to major disagreements on technologies (then) being selected in DRDO for missile-development.

'I'm inclined to tell Ramanna' [the then Minister of State for Defence Research] said SD to me, 'you go your way, I'll go mine. I have an instruction in writing that ISRO work is to be entirely peaceful. I'm sticking to that.'

'I have a programme, a full one', he continued. 'If they have a programme, let me see it. If there is anything we can mesh in the programmes, we can do so. But I do not see any [missile] programme.'

I mentioned to SD that the Defence Research and Development Laboratory (DRDL) (at that stage) seemed to be locked-into liquid propulsion systems.

'What the hell (sic) are they mucking-around (sic) with liquids?' SD let out with annoyance and language uncharacteristic of him. 'If defence really wants something, can they get anything better than SLV-3? Where is their small-missile programme?'

\section{Kalam}

For reasons mentioned variously at places in the bookreferences to this essay ${ }^{4-6}$, the duo of SD and Brahm Prakash, Director of the Vikram Sarabhai Space Centre (VSSC) arranged a relocation to the ISRO Headquarters in Bengaluru of A. P. J. Abdul Kalam, Project Director of SLV-3, and hero of the successful launch on 18 July 1980 of India's first satellite, Rohini.
While at the ISRO Headquarters, Kalam was approached to check out his availability for the Directorship of DRDL, the missiles laboratory of DRDO, in Hyderabad.

SD did not hide his scepticism of the wisdom of Kalam's inclination to accept such an invitation.

Kalam sought the advice of both Rajan and me in a brief conversation in the apron of the old ISRO building a conversation that is etched into our memories. We were both unanimous in our view that Kalam should move to DRDO. It would be good for DRDO, for the country and for ISRO.

Of such impromptu events is history sometimes made.

\section{Sizing of the Solid Propellant Space Booster Plant}

The late Vasant R. Gowariker was the concept-champion and lead designer of the Solid Propellant Space Booster Plant (SPROB) ${ }^{10}$. Located on a corner of the Sriharikota island (SHAR), SPROB casts the solid propellants in the boosters of ISRO's launch vehicles.

A gargantuan facility by 1970s standards, Gowariker's 'oval race-track design' bore close resemblance to that of a similar plant of the Thiokol Corporation, USA; one that cast solid boosters of the US' ICBMs.

Gowariker made a presentation on SPROB to Menon, who was then the interim, 'holding Chairman', of ISRO.

Menon's reaction was what young people today would characterize as 'freaked out'. He did not consider it again and left it to 'Satish to handle'.

Gowariker made his pitch again to the SHAR Review Committee, which had been explicitly set up to prune and sequence earlier plans so as to be accommodated in an extremely tight budget. Now, the design of SLV3, and the envisaged strap-ons for the follow-on ASLV, were only a metre in diameter. Yet, why was Gowariker insistent on a 2 metre capability, requiring large-sized equipment to be very expensively imported with scarce foreign exchange?

There were rows, inside and outside the Committee. These rows were brought, by both protagonist and antagonists, to the notice of both Brahm Prakash and SD.

SD approved the 2 metre capability.

On a later visit to SHAR, I accompanied SD to inspect the deep, large-diameter equipment-caissons that the Department's Civil Engineering Division had impossibly embedded in the sandy soil to accommodate 2 metre diameter boosters.

'There is your silo', SD exclaimed softly, pointing into a caisson as if it were self-evidently capable of such a dual function, 'put SLV in one of those'.

On that visit, SD took me with him on a long drive to the SHAR beach, speaking only of birds, trees and nature on the way. Still smarting from his decision to back the 'Gowariker side', I asked him at the beach why he had brought me there. 'Because it is good for you', he said, picking up and handing me a pretty shell from the beach; 
finally declaiming (to the effect): 'If we do not size SPROB now for two-metre boosters, the imported equipment we need for it will not be allowed to us later.'

\section{On 'going nuclear'}

I have related those recollections of SPROB-in-themaking, as vividly as I am now able, to provide more evidence to disabuse a belief widely held in certain policy-advocating circles that, because SD was Left-ofCentre in his social attitudes - and he was transparently that - he must have been also against India 'going nuclear', if not being something of a pacifist.

But that SD was conflicted in the matter of India going nuclear was apparent. Revealingly, he sent me in early 2000 a review in Nature by Robert Cahn - a leading Cambridge metallurgist whom he knew - of a book by George Perkovich, one of the late Krishnaswamy Subrahmanyam's 'non-proliferation Ayathollahs'. On a copy of the review titled: 'Balancing ambition and restraint: India's struggle with its twin desires to have and to renounce the bomb ${ }^{11}$, was one on which he had side-lined several sections with one which read: 'How could India sustain its self-image as a great civilisation and a nation worthy of a leading place in the international system if America treated it as inconsequential?'

Among the photographs taken at the 1974 Pokhran-I test site, there is one showing SD with then PM Indira Gandhi, and several of those closely associated with that test. That occasion was also the site of an alert that SD provided Indira Gandhi, the consequence of which is related in note ${ }^{12}$.

But SD was firmly against the weaponization of space $^{13}$.

\section{On the Satish Dhawan Space Centre, Sriharikota}

\section{Birds of}

'Whenever my work related to the country's space programme became a little taxing, I went to see the birds of SHAR - and came back feeling happy and invigorated. ${ }^{, 14}$

In the mid-seventies, SD invited Salim Ali, the legendary Bird Man of India, to survey the bird-life on SHAR.

As Secretary of a Committee set-up to review and plan the facilities at SHAR, I was detailed to accompany Salim Ali-with his 'always wrung around his neck' binoculars - on a tour of the island. By the time we returned to base, he had identified several bird types that - Salim Ali said - he had not expected to see so far south. (I, of course, had noticed only some crows.) The cluster-habitats of SHAR's uncommon birds were identified, and marked off-limits to any brick-and-mortar or human intrusions.

\section{Yennadis of}

Binod Agarwal was a social anthropologist engaged with ISRO's Satellite Instructional Television Experiment (SITE) programme. SD detailed him to conduct a social anthropological survey-and-study of the Yennadi tribe, the original inhabitants of Sriharikota island.

Respecting the lifestyle of the Yennadis as revealed in Agarwal's survey - and their (then) preference to continue to live in their extant habitats on the island - meant that their liveability needed to be much improved, besides the thatch of their huts being sprayed with a special chemical which rendered them fire-retardant.

Also, some of the routes of the underground data cables had to be changed, so their routine maintenance did not cause disturbance to those habitats.

'One of my dreams will have been fulfilled', SD said to me after approving those necessary amendments to the SHAR plan, 'if one day a Yennadi becomes the Director of SHAR.'

That appointment is perhaps some years away yet, but in the meantime a Nicobarese is now in-charge of ISRO's ISTRAC station at Car Nicobar in the Andaman Sea.

\section{An afterword}

SD was instrumental in the setting-up of the Test Pilot School of the Indian Air Force (IAF), as also its Institute of Aviation Medicine, which latter was upgraded to train India's first astronaut, test pilot Squadron Leader Rakesh Sharma.

When the then PM Indira Gandhi accepted - mainly for geo-strategic reasons - an offer from the (then) Soviet Union to fly an Indian astronaut in a Russian Soyuz space capsule to its Salyut space station, the late T. N. Seshanthe then Additional Secretary, DoS - informed SD of that decision when they were both in Sriharikota. 'Prof. Dhawan spun around on his heel', Seshan related to me, exclaimed: 'what?' and left directly for Delhi from Madras.

India's astronaut programme with the Soviets was administered and executed by the IAF, not by ISRO.

In 1983, on a balmy day cruise on-board ORV Sagar Kanya, the then Governor of Maharashtra, retired Air Chief Marshall Idris Hasan Latif, lauded the role of the IAF in the astronaut programme. Addressing a compact on-board group that included me, the Governor let it be known that opposition to the astronaut programme came from what he characterized as 'the strangest of quarters'.

What would have been SD's assessment of the scientific, or even geopolitical, returns from ISRO's current Ganganaut programme?

I am confident of the correctness of my guessanswer. 
1. Rajan, Y. S., Satish Dhawan, 1920-2002. In Biographical Memoires of the Indian National Science Academy, INSA, 2005, vol. 28.

2. Profile for the Decade 1980-1990, Government of India, Department of Space, 1981.

3. Antrix Corporation (https://www.antrix.co.in) and the recentlyformed NewSpace India Limited (NSIL)

4. Manoranjan Rao, P. V. and Radhakrishnan, P., A Brief History of Rocketry in ISRO, Universities Press (India) Private Limited, 2012.

5. Narayanan, N. with Ram, A., Ready to Fire: How India and I Survived The ISRO Spy Case, Bloomsbury Publishing (India) Limited, 2018.

6. Sandlas, V. P., The Leapfroggers, Harper Collins, India, 2018.

Younger readers, particularly, of the above three accounts might wonder why certain novel, if not revolutionary, paths of technology development for low-cost access to space were not taken.

Responding to a query from me in November 1981, on why we were (then) shying from such paths (some possibilities of which I suggested might be followed), SD responded in this hand-written note: "The Gossamer Condor [an ultra-light, human-powered aircraft] is an adventure of the spirit, not a "useful" development Percheron [a very low-cost experimental satellite launcher] purports to be a "useful" \& cheap deal - when it works [it did not] are essentially based on the level of technology available readily in the U.S. because of all that has gone before. In ISRO we cannot at this stage take any quantum jumps - the intellectual \& industrial base is sub-critical in quality re. the first \& quantity re. second.'

7. Siddhartha, V., The evolution of science and technology in India since Independence. In UNESCO History of Humanity (eds Gopal, S. and Tikhvinsky, S. L., co-edited by Abu-Lughod, I. A. et al.), Scientific and Cultural Development, Volume VII, The Twentieth Century, Routledge, 2008.

8. When I asked the late B. V. Sreekantan, an ex-Director of TIFR, why KC had moved to Zurich, 'for personal reasons of being able to fund his children's education abroad', he replied. 'Otherwise
Bhabha would have selected him as his successor Director of TIFR', added Sreekantan.

9. Personal communication of 20 May 1996 to me from Secretary to Prof. K. Chandrasekharan.

10. Nagappa, R. et al. (Vasant R. Gowariker (1933-2015). Curr. Sci., 2015, 108(4), 732-733.

11. Cahn, R., Balancing ambition and restraint: India's struggle with its twin desires to have and to renounce the bomb. Nature, 2000, 403(17), 401-402.

12. At a turn-corner of Ulsoor Lake in Bengaluru, on a traffic island in the administrative charge of an Army detachment nearby, there was a beautiful large tree. When a 'plot' to cut down that tree became known, I shot-off a telex to SD who was then with PM Indira Gandhi at the Pokhran-I test site. At that otherwise barren site she had noticed some large shrubs and remarked to those assembled: 'I hope those are not going to be cut'. SD pulled out from his pocket my telex message forwarded to him in Pokhran. 'But see what they are doing in Bangalore', A. K. N. Reddy who, with Zaffar Futhehally, was an active member of the 'Bangalore Clean and Green' movement told me SD said to the PM, while showing her my telex. An order came down from on high, and that tree was saved (it is now gone).

13. Dhawan, S., For humanity's benefit and not for space weaponry. New Perspectives, 5/88, Journal of the World Peace Council, Helsinki. Based on two lectures SD delivered to the Fourth National [US] Symposium on 'Space Challenge 88', held in April 1988 under the auspices of the United States Space Foundation in Colorado Springs. One of SD's lectures concludes: 'A truly cooperative mission to Mars would represent a far greater contribution to the World's Space Experience than would a US-Soviet competition in Space Weaponry'. He would surely have expressed disappointment at the current clutch of geopolitically driven, but the wastefully competitive, national space missions to Mars.

14. Quote from SD on the back cover of: Satish Dhawan: A Cherished Association With NAL, National Aerospace Laboratories, Bangalore, March 2002.

doi: $10.18520 / \mathrm{cs} / \mathrm{v} 119 / \mathrm{i} 9 / 1452-1456$ 